\title{
EL SIGNIFICADO ASOCIATIVO EN LA PUBLICIDAD
}

Franca Bizzoni

"La publicidad es el alma del comercio", reza un dicho muy conocido, subrayando el concepto de que sólo el comerciante que presenta su producto en forma atractiva para el público consumidor es un buen vendedor y sin embargo, muy probablemente, un mentiroso. No obstante, la publicidad ha llegado a ser mucho más que esto: actualmente implica grandes capitales e involucra muchas personas, llega a todo tipo de público y ejerce una fuerza extraordinaria de condicionamiento; difunde modelos de vida, mitos, creencias, modifica costumbres y obliga a consumos totalmente superfluos, so pena de la exclusión de la comunidad, por medio de un lenguaje de eslogans, cuyos métodos de sugestión han sido objeto de profundos y numerosos tratados.

Dentro de la compleja semiología del mensaje publicitario, que se compone de diferentes sistemas de significación, este trabajo se limitará a atender sólo el aspecto relacionado con el material verbal inscrito en el anuncio. Se mencionarán a veces otros aspectos importantes, pero sin analizarlos, por ser más conveniente para ellos un análisis de tipo semiológico, análisis que escapa a la intención y posibilidades de este ensayo. En consecuencia, se intentará considerar la parte lingüística de los mensajes publicitarios examinados, prescindiendo en lo posible de su integración con signos de otra índole que aparezcan en los mismos.

Una de las características más importantes del lenguaje de la publicidad es que no tiene la función de comunicar información, sino casi exclusivamente la de orientar al receptor hacia un determinado producto. En otras palabras, en el mensaje publicitario el acto ilocutivo, es decir, la intención del productor del mensaje, siempre es el mismo: sugerir, invitar o imponer al decodificador la compra de un producto. De aquí la importancia que el creador de publicidad da al aspecto formal del texto y a su construcción retórica.

Lisa Block de Behar, en El lenguaje de la publicidad, menciona algunos de los rasgos estilísticos característicos de este lenguaje:

Transformación de palabras, voces ajenas, términos abstrusos, derivación y composición nada paradigmáticas, basadas en raíces heteróclitas, sintaxis heterogéneas, un fonetismo que registra entonación, acentos y fonemas pronunciados con intención apelativa o 'impresa'... concurren en forma 
deliberada a crear en el receptor un estado de ánimo especialmente apto para provocarlo, estimularlo, convencerlo y persuadirlo para actuar en un sentido concreto y determinado. ${ }^{1}$

Tomando en cuenta que cada cultura se estructura en sistemas semánticos formados por oposiciones y cadenas connotativas, ${ }^{2}$ se propone aquí analizar el aspecto lingüístico de los mensajes publicitarios con base en su significado asociativo, de acuerdo con la subdivisión del "significado" propuesta por Geoffrey Leech. ${ }^{3}$ Él divide el "significado", en su sentido más amplio, en siete tipos diferentes: conceptual, connotativo, estilístico, afectivo, reflejo, colocativo y temático. Veamos brevemente cómo Leech define cada uno de estos tipos de significado.

El significado conceptual se refiere al contenido lógico, cognitivo o denotativo de un elemento léxico, y parece organizarse en rasgos distintivos, en forma similar a la clasificación de los fonemas de una lengua. Por ejemplo, el significado conceptual de la palabra MUJER podría definirse por medio de los rasgos thumano, +adulto, -masculino, distinta de la palabra MUCHACHA definida por los rasgos thumano, -adulto, -masculino. Esta identificación del significado conceptual de un vocablo es similar a la de los fonemas: /b/ se representa formado por el conjunto de rasgos +bilabial, toclusivo, +sonoro, distinto de / $\mathrm{p} /$ definido por los rasgos +bilabial, +oclusivo, -sonoro. El significado connotativo incluye el conceptual más el conjunto de sentidos atribuidos a un referente por un individuo, un grupo social o toda una comunidad social. Las connotaciones dependen, por lo tanto, de la experiencia personal, los conocimientos y la sociedad, y por eso son inestables e indeterminadas.

El significado estilístico es el que comunica un enunciado, un pasaje, un trozo de lengua en relación a las circunstancias sociales. Se refiere a los diferentes niveles de uso y dimensiones estilísticas dentro de una misma lengua, con base en los parámetros: situación de uso, distribución geográfica de los hablantes, distribución y estratificación social de los participantes en el evento comunicativo. Desde este punto de vista se descodifican los estilos formal, coloquial, poético, burocrático, etc.

En cuanto al significado afectivo, es el que refleja los sentimientos y actitudes del hablante y se puede codificar a través de la selección de sinónimos, construcciones sintácticas, patrones entonativos, tonos de voz, uso de interjecciones.

Se habla de significado reflejo cuando una palabra o una expresión tienen varios sentidos conceptuales según diferentes contextos y uno de ellos

1 Lisa Block de Behar, El lenguaje de la publicidad. México, D. F., Siglo XXI Editores, 1973, pp. 27-28.

2 Cf. Humberto Eco, "Analisi semantico di un caso pubblicitario", SIPRA, n. 1, 1972.

3 Geoffrey Leech, Semantics. London, Penguin Books, 1974, pp. 10-27. 
se asocia, contamina otro. Sobre este tipo de significado se basan los albures, los chistes de doble sentido, las alusiones poéticas.

El significado colocativo, a su vez, se compone de las asociaciones que una palabra adquiere a causa de los significados de los vocablos que tienden a aparecer en su entorno. En otras palabras, es el que permite decir una. ragazza carina (una bonita muchacha) o una bella ragazza (una muchacha guapa), pero sólo acepta un bell'uomo (un hombre guapo).

El último tipo de significado propuesto por Leech es el temático, que se transmite a través de la forma en que el emisor organiza su mensaje en cuanto a orden, énfasis y foco, y por lo tanto está estrictamente relacionado con la selección de estructuras sintácticas. Finalmente, Leech agrupa los significados connotativo, estilístico, afectivo, reflejo y colocativo en una sola. categoría: la de significado asociativo, refiriéndose a la teoría asociacionista de conexiones mentales basadas en la contigüidad de experiencias.

Con la aplicación de esta categoría del significado asociativo a un análisis del lenguaje de la publicidad, se intenta demostrar cómo en la creación deun mensaje publicitario el emisor tiene presente que el lenguaje empleado puede suscitar asociaciones semánticas (y consiguientes reacciones) diferentes, basadas en presuposiciones y experiencias diversas, ligadas a factores culturales y afectivos variables.

Empecemos por ver cómo de esto nace, entre otras características del lenguaje de la publicidad, la necesidad de diferenciarlo según el tipo de público al cual se dirige, tomando en cuenta no sólo los macrosistemas sino también los microsistemas culturales, que varían de acuerdo con el gruposocial y a veces de individuo a individuo. Veamos, por ejemplo, las diferencias de lengua entre un mensaje dirigido a un público supuestamente compuesto en su mayoría por hombres, y otro para el ama de casa:

ENTRA NELLA NUOVA BETA. GUIDERAI UNA NUOVA LANCIA. NUOVA LANCIA BETA $\beta 1600,2000$.

(Entra en la nueva Beta. Manejarás una nueva Lancia. Nueva Lancia Beta $\beta 1600,2000$.

Este mensaje abre con una invitación -pero expresada con un imperativo, una forma verbal ampliamente usada en el ámbito publicitario- a entrar en un nuevo automóvil, indicado por una metonimia ${ }^{4}$ BETA = LANCIA,

4 "La metonimia é la sostituzione di un termine co nun altro che ha rapporto di continguitá col primo; ad esempio attraverso lo scambio dell'effetto per la causa, della cosa. per la persona." A. Marchese y A. Sartori, Il segno e il senso. Milano, Principato, 1970, p. 448. 
que se aclara en la segunda parte: GUIDERAI UNA NUOVA LANCIA, para reintegrarse al lenguaje normal en la tercera: NUOVA LANCIA BETA 1600, 2000 . Este anuncio prosigue con un largo texto más informativo, que subraya las prestigiosas cualidades del nuevo automóvil y sus datos técnicos más modernos. Todo esto empleando un léxico muy escogido aunque tomado del nivel medio del lenguaje, sin neologismos:

estetica esterna... il fascino della novitá... eleganza in automobile... accuratezza di una finizione... arditezza... stato di salute...

(estética exterior... el encanto de la novedad... elegancia en automóvil... esmero en un acabado... dinamismo... estado de salud...)

algunos términos técnicos:

calandra... plancia di comando... sistemi anticorrosione... livelli di insonorizzazione...

(parrilla... tablero... sistemas anticorrosivos... niveles de aislamiento sonoro...)

y algunas pa'abras en idioma extranjero:

new-look. . control-system... restyling

que le confieren un refinamiento exótico.

El mensaje está elaborado para un automóvil costoso y, por lo tanto, está destinado a un público no sólo supuestamente masculino, sino también con elevado poder adquisitivo. En consecuencia se usa un lenguaje rebuscado, un poco "snob", con tecnicismos y palabras extranjeras, que claramente persigue dos fines: si por un lado se dirige al experto automovilista, al hombre que no tiene problemas para leer en italiano o en inglés (nótese, en passant, que las palabras inglesas están perfectamente integradas al texto en italiano, incluso desde el punto de vista tipográfico); por el otro, el hecho de que el automobilista esigente sea él mismo ( $E^{\prime}$ la Lancia che aspettavi - Es la Lancia que esperabas) lo halaga y al mismo tiempo lo afianza en la búsqueda de su identidad personal.

Pasemos ahora a examinar la publicidad de la lavadora Miele. Fn la primera pregunta

(La metonimia es la sustitución de un término por otro que tiene relación de conitgüidad con el primero; por ejemplo, a través del intercambio del efecto con la causa, de la cosa con la persona.) En el caso analizado, se sustituye el nombre del modelo por la marca. 
Cosa significa per me, donna di casa, poter contare sul comando elettronico delle lavatrici Miele?

(¿Qué quiere decir para mí, ama de casa, poder contar con el mando electrónico de las lavadoras Miele?)

ya se hace explícito el "blanco" del mensaje, que es el ama de casa, lo cual' presupone escasos conocimientos de electrónica y de técnica en general. También las otras preguntas:

Il comando elettronico é particolarmente complicato?

(¿El mando electrónico es particularmente complicadlo?)

Cos'é un programma "Breve-economico"?

(¿Qué es un programa “breve-económico”?)

se basan en esta presuposición, confirmada por las respuestas, en las cuales. se emplea un lenguaje sencillo, con sólo dos tecnicismos: "microcomputer" y "sensor", vocablos, por lo demás, muy frecuentes, que han perdido en parte su sabor técnico.

La figura retórica que aquí se usa para explicar la importancia del comando elettronico es una paráfrasis de este mismo sintagma:

lo svolgimento automatico del programma viene controllato elettronicamente da un nuovo microcomputer.

(el desenvolvimiento automático del programa está controlado electrónicamente por una nueva microcomputadora.)

No se aclara nada sobre el funcionamiento de la lavadora, pero se le da validez científica a la respuesta mediante el uso de un término técnico, al mismo tiempo que se crea un sentimiento de respeto en el receptor.

En la última respuesta:

Il programma "breve-economico" permette di lavare piccoli quantitativi di biancheria consumando meno acqua, meno energia e meno detersivo.

(El programa "breve-económico" permite lavar pequeñas cantidades de ropa gastando menos agua, menos energía y menos detergente.)

tampoco hay información sobre cómo se realiza el programa "breve-econó- 
mico": sólo hay un discurso de tipo argumentativo, en el cual la figura iterativa (Cos'é un programma "breve-economico? Un programma "breve-economico."...) y más adelante meno acqua, meno energia a meno detersivo, estos menos..., menos..., menos..., cumplen la función de redundancia persuasiva.

El cierre del mensaje también merece un poco de atención:

se il meglio non ti basta.

(si lo mejor no te basta.)

Aquí hay una construcción hipotética que rompe el sistema sintáctico del italiano, porque realiza sólo la prótasis, o sea la hipótesis, y deja implícita la apódosis, o sea la consecuencia: esto crea una fuerte suspensión persuasiva. Se trata en realidad de un empleo muy sutil de la presuposición, en que se compara el producto con todos los demás de la misma línea, aboliéndose sin embargo la referencia al segundo término de la comparación. La presuposición implícita es que "ya existe lo mejor en este campo, pero tú mereces lo mejor de lo mejor", presuposición reiterada con la personalización del mensaje mediante el uso del pronombre de segunda persona singular (tu), nunca antes empleado en el texto, a pesar de la pregunta de apertura en primera persona (Cosa significa per me...).

Uno de los procedimientos más difundidos en la publicidad, con base en por lo menos dos de los cinco tipos de significado que configuran la categoría del significado asociativo - el connotativo y el reflejo- es el de construir mensajes que, explotando la polisemia y la ambiguiedad de signos lingüísticos y construcciones sintácticas, permitan una lectura a diferentes niveles. ${ }^{5}$

Veamos algunos ejemplos:

VANNUCCI, l'altra pelle che ti appartiene vannucci oggetti in pelle strettamente personali

(Vannucci, la otra piel que te pertenece

Vannucci objetos de piel estrictamente personales)

Aquí pelle tiene el significado de piel animal para fabricar objetos, pero todo el mensaje juega con el otro sentido de piel, en su connotación huma-

5 Cf. Maria Corti, "Il linguaggio della pubblicitá" en G. L. Beccaria (ed.), I linguaggi settoriali in Italia. Milano, Bompiani, 1973. 
na: de hecho, ésta es la piel que nos pertenece. En la primera parte de la última oración oggetti in pelle aclara de qué piel se está hablando, pero se sigue explotando el rasgo "humano" en strettamente personali.

Otro ejemplo:

Diamanti.

Per l'uomo che ha polso. E non lo nasconde.

(Diamantes. Para el hombre que tiene pulso. Y no lo esconde.)

En este mensaje se explota la polisemia de polso, en su significado conceptual (referencial) de "muñeca" y el significado metafórico que asume en el sintagma "hombre de pulso"; así, la palabra polso suscita en el lector asociaciones de fuerza, virilidad, hombría. La ambigüedad continúa en el último enunciado $E$ non lo nasconde, o sea, el hombre que tiene "pulso" no lo esconde, así como no esconde su muñeca con mancuernillas de diamantes. Una vez más parecería un mensaje destinado a un cliente de gustos refinados, que sabe lo que quiere, etcétera, etcétera. En realidad, está dirigido al lector común que probablemente no posee tales cualidades y necesita productos de nivel supuestamente superior para sentirse seguro de sí mismo, de su buen gusto, su virilidad, su anticonformismo.

Giorgio A. Cardona en La lingua della pubblicitá, a propósito de un anuncio publicitario elaborado para la revista Playboy, dice:

E' infatti ovvio che il lettore di Playboy non é affatto un uomo sicuro di sé, che sa quel che vuole, che non ammette che altri scelgano per lui, ecc., proprio perché una figura cosí stilizzata non puó esistere che nella pubblicitá. Semmai il lettore é tutto il contrario: un uomo insicuro che deve continuamente essere rassicurato... Dunque il messaggio é rivolto innanzitutto al lettore comune, a quello privo proprio delle doti che sono appunto date per scontate per il lettore abituale, medio di Playboy. ${ }^{6}$

Veamos ahora otro ejemplo de doble lectura:

6 Giorgio R. Cardona, La lingua della pubblicitá. Ravenna, Longo Editore, 1974, p. 13. Trad.: En efecto, es obvio que el lector de Playboy no es de ninguna manera un hombre seguro de si, que sabe lo que quiere, que no admite que otros elijan por él, porque una figura tan estilizada no puede existir sino en la publicidad. Si acaso, el lector es todo lo contrario: un hombre inseguro que constantemente debe ser tranquilizado... Entonces el mensaje será dirigido antes que nada al lector común, al que no posee esas cualidades que se dan por sentadas precisamente en el lector habitual, medio de Playboy. 


\section{GRAPPA CARPENE MALVOLTI.}

La forma e la sostanza.

Per voi conta di piú il corpo o l'anima?

L'anima, d'accordo. Perché un'anima cosi, col suo morbido bouquet, col suo gusto sottile e inimitabile, scioglie ogni dubbio. Sono cose risapute da cent'anni. Eppure anche l'occhio vuole la sua parte. Se non altro per riconoscere certe qualitá a prima vista.

Non vi sembra?

Grappa Carpené Malvolti. Grappa nata bene.

(La forma y la sustancia.

¿Para ustedes cuenta más el cuerpo o el alma?

El alma, de acuerdo. Porque un alma así, con su suave bouquet, con su sabor sutil e inimitable, resuelve cualquier duda. Son cosas que se saben desde hace cien años. Sin embargo, también el ojo quiere su parte. Si no fuera por otra cosa, para reconocer ciertas cualidades a primera vista. ¿No les parece?

Grappa Carpené Malvolti. Grappa nacida bien.)

Este mensaje abre con una frase que podríamos definir como "filosófica": la forma e la sostanza. Sigue con una pregunta retórica y una respuesta que se mantiene en el mismo campo de conocimiento: corpo y anima son dos lexemas con significados peculiares en el lenguaje filosófico. En el tercer enunciado (Perché un'anima cosi...dubbio), el significado de anima como "parte espiritual del hombre, existente pero no visible", se desplaza al sabor del licor, ya que éste cuenta más que el aspecto exterior, el cuerpo, o sea la botella.

Desde el punto de vista formal, la transferencia de significado se realiza empleando las figuras retóricas de la iteración (L'anima, d'accordo. Perché un anima cosi...) y de la sinestesia (morbido bouquet... gusto sottile) por lo que se refiere a anima, y simplemente una frase hecha, un estereotipo lingüístico (...l'occhio vuole la sua parte), para indicar el cuerpo. En otras palabras, todo el anuncio se construye alrededor de la dicotomía anima/ corpo, forma/sostanza, empleándose un lenguaje preciosista, rico, que atrae la atención del lector, en la parte que se refiere al "animal/sostanza", la más importante, y un lenguaje común, cuando se refiere al cuerpo/forma.

Por ńltimo, analicemos el cierre de este mensaje: Grappa Carpené Mal- 
volti. Grappa nata bene. En italiano, dos apellidos casi siempre significan nobleza; este sentido se confirma asociándolo a nata bene, nacida de buena y rica familia y, por lo tanto, de alta calidad. Este mensaje explota, pues, por lo menos dos asociaciones semánticas de diferente nivel, de acuerdo con las experiencias culturales y sociales del lector: la de forma/sostanza - corpo/ anima, ligada probablemente a su nivel de instrucción, y la de nobleza/alta calidad, ligada en cambio a sus prejuicios sociales.

Muchos menos articulado lingüísticamente es el mensaje de este ejemplo:

Perché la tua dieta non vada

a farsi friggere.

(Para que tu dieta no fracase, vaya a freír espárragos)

probablemente porque está destinado a la mujer: una mujer de cultura media, no integrada al proceso productivo y sin compromisos sociales o politicos. Es evidente aquí que el publicista, como en otros comerciales de productos similares o de todas maneras dirigidos a la mujer, trata de instrumentar el sentimiento de frustración del ama de casa para proponer el producto en función consoladora: se trata de la tua dieta que es importante. Se subraya, más bien, el papel de la mujer en su manifestación de "hembra", sin aludir a las de madre, esposa, compañera, etc., que sin embargo se presentan con frecuencia en la comunicación publicitaria. ${ }^{\top}$

Desde el punto de vista semántico, el anuncio gira alrededor de friggere (freir): en la estructura superficial de la frase es usado dentro de una expresión coloquial que significa, entre otras cosas, "fracasar", pero su significado conceptual o referencial es el de "cocinar en aceite hirviendo" y, por lo tanto, perfectamente apropiado a la publicidad de un aceite. A esta particular relación asociativa entre el significado referencial y el traslado al estereotipo se confía la realización de la función conativa del mensaje.

Otra variante de este mismo procedimiento, o sea, la explotación del doble sentido de una palabra o frase que permite una doble lectura, es el de cambiar un término en una frase hecha. Las expresiones hechas y los dichos populares más difundidos constituyen un material particularmente conveniente para crear esa sorprendente imprevisibilidad que busca la publicidad. Se trata de un procedimiento que utiliza una fórmula ya conocida modificándola para desviar la atención del lector hacia el producto.

7 Ver el análisis del anuncio de las sopas Knorr por U. Eco en La struttura assente. Milano, Bompiani, 1968, pp. 184-185. 
Un ejemplo de este tipo de elaboración publicitaria es el siguiente:

Dimmi che Maruman scegli ... e ti diró chi sei. (dime qué Maruman escoges ... y te diré quién eres)

en el cual Maruman scegli evoca el tradicional ...con chi vai (dime con quién andas).

Desde el punto de vista puramente comunicativo, en su artículo "L'innovazione linguistica in pubblicitá", Giorgio $R$. Cardona señala que lo importante de este procedimiento no es que "il destinatario riconosca l'origine, ma che avverta un andamento familiare, che provi una sensazione di déjà vu'." 8

El lenguaje de la publicidad quema rápidamente las formas lingüísticas que produce $y$, por lo tanto, tiene que crear constantemente algo nuevo, recurriendo a las posibilidades expresivas del código lingüístico que usa, para captar la atención del público. Una de las figuras retóricas más explotadas en este campo es la de la sinestesia, en que se unen dos palabras tomadas de dos esferas sensoriales distintas.

He aquí un ejemplo de sinestesia:
spacca lo sporco!
e assicura piú igiene
(iquiebra la mugre!
y asegura más higiene)
CALINDA clorat

Spaccare es un verbo que, entre sus reglas de selección léxica, requiere como objeto un lexema con rasgo semántico +sólido: combinarlo con un elemento no sólido y, por tanto, no previsible como en este anuncio, viola las reglas de restricción y crea un momento de perplejidad, suficiente para atrapar al lector.

Otro ejemplo de sinestèsia:

$$
\text { SILTAL }
$$

\section{LA SCELTA MATURA}

(SILTAL la elección madura)

8 Giorgio R. Cardona, "L'innovazione linguistica in pubblicitá", SIPRA, n. 3, 1979. Trad. "el destinatario reconozca el origen, sino que note una forma familiar, que pruebe una sensación de 'dejá vu'." 
El adjetivo usado - matura - se combina normalmente con lexemas que denotan fruta y ésta es la asociación que se quiere evocar, lo cual queda confirmado en el contexto visual, que presenta una pera que está por caerse de madura. La combinación scelta matura no es totalmente nueva porque en el lenguaje común ya existen construcciones análogas, en las cuales maturo/a se une a sustantivos de otra naturaleza, que no se refieren a fruta, como en decisione matura, giovane maturo (decisión madura, joven maduro). En estos sintagmas el adjetivo adquiere otro rasgo, relacionado más bien con la psicología. Aquí se explotan los dos significados: el que llamaremos conceptual (matura + fruta) y el metafórico (maturo + rasgo psicológico).

Un tipo especial de sinestesia es el ejemplificado en el anuncio que sigue:

\section{Vallé}

Tenerezza da spalmare e da gustare.

\section{(Vallé. Ternura para untar y para saborear)}

en que se presenta un intercambio de rasgos semánticos. En efecto, spalmare, usado en su significado referencial, requiere un paciente con rasgos semánticos + concreto +blando (se unta la mantequilla, por ejemplo); gustare, a su vez, requiere en función objeto un lexema +concreto, pero además está relacionado con la esfera sensorial del gusto. Tenerezza, en cambio, tiene un significado complejo, formado por muchas asociaciones también de tipo afectivo: se refiere a una cualidad atribuible a lexemas con rasgo thumano o -humano. El mensaje, entonces, explota a nivel superficial la novedad de la combinación tenerezza + spalmare y tenerezza + gustare; a nivel más profundo, el significado connotativo de tenerezza, o sea, ternura + suavidad + blandura.

También me parece interesante examinar el anuncio siguiente:

$$
\begin{aligned}
& \text { Versa il sole, } \\
& \text { versa SOL. } \\
& \text { (Vierte el sol, } \\
& \text { vierte Sol) }
\end{aligned}
$$

porque explota varios niveles de significado. En el primer enunciado, Versa il sole, hay un desplazamiento de significado realizado con una metonimia: sol $=$ calor $=$ beneficios $=$ pureza del producto, debida a una relación de contigüidad lógica. ${ }^{9}$ El segundo enunciado, Versa Sol, usa una aliteración para no romper el ritmo del eslogan (versa - versa), y una metonimia, en

9 Gaetano Berruto, La semantica. Bologna, Zanichelli, 1976, p. 117. 
la cual la marca SOL sustituye al producto (aceite) para darle más densidad. Todo esto va relacionado con el valor simbólico del sol, que en el hombre inurbado (de la ciudad) suscita asociaciones de luz, libertad, naturaleza, que llegan a coincidir en su subconsciente con ese aceite o con una lata de jitomate, como en:

\author{
"Pummaró" \\ ha il sole dentro \\ (perché fatto nella vera stagione dei pomodori) \\ ("Pummaró" tiene el sol adentro \\ porque está hecho en la verdadera temporada \\ de los jitomates)
}

Aquí el publicista emplea una metonimia que juega sobre

la contiguitá di alcuni campi semantici, donde la compresenza di alcuni termini 'sole, natura, primavera, verde, vent'anni, salute, serenitá'

che si collegano ... a evocare gli ideali mi-

tici e utopici latenti nell'uomo contemporaneo.10

Otro recurso muy usado en la comunicación publicitaria, por su potencia evocadora, es el empleo de palabras y temas que se refieren a la problemática socio-política actual. En efecto, la propaganda raras veces es totalmente original: trata siempre de hacerse eco de cualquier hecho nuevo producido en el terreno técnico, ideológico, artístico, científico, político, etc., que ya se encuentra presente en el receptor por el éxito alcanzado desde su propio campo. De otra forma, el exceso de novedad puede comprometer la comprensión del mensaje y suscitar el fracaso de sus exhortaciones por medio de una situación extraña, paar la cual el usuario no estaba preparado.

Un ejemplo de este tipo de explotación es el siguiente:

Incontro al vertice tra linea e colore.

(Encuentro en el vértice entre línea y color.)

donde se utiliza un sintagma tomado del lenguaje político (Incontro al vertice) muy de moda y, por lo tanto, presente en el subconsciente del lector.

10 Maria Corti, op. cit., p. 132. Trad. "la contigüidad de algunos campos semánticos, donde (de ahf) la presencia simultánea de unos términos 'sol, naturaleza, primavera, verde, veinte años, salud, serenidad' que se unen ...para evocar los ideales míticos y utopísticos latentes en el hombre contemporáneo." 
Aquí se destaca la importancia de "línea" y "color" y al mismo tiempo, se debilita la connotación política del sintagma empleado, reduciéndolo a un eslogan vacío.

Otra ejemplificación de como la publicidad instrumenta los temas actuales para sus fines persuasivos puede verse en el siguiente mensaje:

"Papá, se fai il bavo ti do

un pezzettino di biccotto Montefioe"

(Papá, si te portas bien te doy

un pedacito de galleta Montefioe)

en el cual se evoca el mundo infantil incluso en la reproducción gráfica de la forma de hablar típica de los niños: bavo y biccotto Montefioe en lugar de bravo y biscotto Montefiore representan los "errores" característiicos de un niño que no ha adquirido aún todos los rasgos distintivos del sistema fonológico del italiano, en este caso el fricativo y el vibrante que normalmente aparecen al finalizar esta etapa de adquisición del lenguaje.

Es evidente que aquí el publicista quiere suscitar en la mente del lector un conjunto de sensaciones afectivas ligadas a su propia infancia, y de relaciones culturales, ligadas a su experiencia actual (año internacional del niño, etc.) que van a integrarse al significado global que él le atribuya a este mensaje.

Como hemos visto, la comunicación publicitaria puede parecer muy innovadora en cuanto a los recursos lingüísticos que usa: en realidad "parla un linguaggio giá parlato in precedenza, e proprio per questo risulta comprensibile." 11 No es ni quiere ser una fuente autónoma de innovaciones lingüísticas, porque reproduce tendencias ya presentes en la lengua italiana (Tullio De Mauro lo define "linguaggio subalterno"),12 o sea, se apoya en soluciones ya codificadas o en proceso de codificación en la lengua. Para sus fines de persuasión, el lenguaje de la publicidad acentúa las posibilidades expresivas del idioma: a nivel léxico, inventa vocablos mediante el empleo de prefijos y sufijos, la composición y yuxtaposición de sustantivos, el encaje de una parte de palabra en otra, etc.; a nivel morfo-sintáctico, refuerza y amplía construcciones ya presentes, pero esporádicas, en la lengua común, contribuyendo a ese mismo proceso codificador o en el que se inserta: así, difunde y multiplica adjetivos en función adverbial, sintagmas en que se han eliminado las preposiciones e incluso los nexos de subordinación, una sintaxis de tipo lineal, paratáctico, etc.

El lenguaje publicitario no sólo recurre a lo ya adquirido en los sistemas

11 Umberto Eco, La struttura assente, p. 187.

12 Tullio De Mauro, "Un linguaggio subalterno", SIPRADUE, n. 12, 1967. 
fonológico, léxico y morfo-sintáctico, sino también, desde el punto de vista de su estructuración retórica, recupera y emplea figuras y argumentos de la retórica clásica, ${ }^{13}$ aplicándolos a las posibilidades semánticas de la lengua en que se expresa, mediante la explotación de las cadenas connotativas que cada comunidad lingüística estructura por medio de experiencias sociales y culturales.

\section{BIBLIOGRAFIA CONSULTADA}

ALTIERI-BIAGI, M. Luisa, "Note sulla lingua della pubblicitá", Lingua Nostra, Vol. XXVI, Fasc. 3, Settembre 1965, Firenze, Sansoni.

BERRUTO, Gaetano, La semantica. Bologna, Zanichelli, 1976.

___, "Teoria della lingua pubblicitaria", Sipra, n. 4, 1973.

BLOGK DE BEHAR, Lisa, El lenguaje de la publicidad. México, D. F., Siglo XXI Editores, 1973.

CARDONA, Giorgio R., "L'innovazione linguistica in pubblicita", Sipra, n. 3, 1972.

—, "Au lingua della pubblicitá, Ravenna, Longo Editore, 1974.

CASTAGNOTTO, UGO. "Pubblicitá e operativitá semantica", Sipradue, n. 9, 1967.

CORTELAZZO, Mario, "Lingua pubblicitaria e italiano comune", Sipra, n. 4, 1973.

CORTI, Maria, "Il linguaggio della pubblicitá", Beccaria, Gian Luigi (ed.) I linguaggi settoriali in Italia. Milano, Bompiani, 1973, pp. 119-139.

DE MAURO, Tullio, "Un linguaggio subalterno", Sipradue, no. 12, 1967.

ECO, Umberto, La struttura assente. Milano, Bompiani, 1968.

-. "Analisi semantica di un caso pubblicitario", Sipra, n. 1, 1972.

FOLENA, Gianfranco, "Analisi linguistica di contesti pubblicitari 'Metti un tigre nel motore" "', Sipradue, n. 11, 1967.

GRASSI, Corrado, "Linguaggio pubblicitario vecchio e nuovo", Sipradue, n. 2, 1967.

—. "Linguaggio pubblicitario e storia della lingua italiana", Sipradue, n. 11, 1967.

LEECH, Geoffrey, Semantics. London, Penguin Books, 1974.

MARCHESI, A.-SARTORI, A., Il segno $e$ il senso. Milano, Principato Editore, 1970.

MEDICI, Mario, "I grandi temi del tempo attuale nell'espressione pubblicitaria", Siprauno. n. 4, 1973.

"Bibliografia degli scritti sulla lingua della pubblicitá", Sipra, n. 4, 1973.

SIMONE, Raffaele, "Publicitá e creativitá linguistica”, Sipra, n. 2, 1972.

13 U. Eco, La struttura assente, p. 167.

N.B. Todas las traducciones son de la autora de este trabajo. 